\title{
Universalismo entre religiões e modernidade: a fundamentação do universalismo epistemológico-moral por meio da cooperação entre razão e religião
}

\author{
Universalism between religions and modernity: the foundation of the \\ epistemological-moral universalism by means of the cooperation of reason and \\ religion
}

\author{
Leno Francisco Danner* \\ Agemir Bavaresco ** \\ Fernando Danner ${ }^{* * *}$
}

\begin{abstract}
Resumo
O artigo tem por objetivo desenvolver uma crítica à noção de modernidade ou racionalismo moderno apresentada em teorias da modernidade contemporâneas, marcada pela ideia de uma autonomia e de uma autossuficiência da razão no que tange à fundamentação de uma noção vinculante de universalismo epistemológico-moral, criticando-se a percepção, própria a essas teorias, de que o racionalismo profano e secularizado, concebido como uma perspectiva imparcial, neutra, formal e impessoal em termos axiológico-metodológicos, seja suficiente para garanti-lo, sem necessidade da religião e da metafísica. Com isso, seu segundo objetivo consiste em argumentar em favor de um universalismo político-religioso que aponta para a incapacidade dessa noção purista e independente de razão em gerar e sustentar, sem o próprio trabalho de fundamentação e de aplicação metafísico-religioso, um conteúdo universal de direitos humanos. O trabalho escora-se em revisão bibliográfica de teorias da modernidade contemporâneas, a partir de uma crítica a seu pressuposto central, a autonomia, a autorreferencialidade e a autossuficiência da razão relativamente à religião e à metafísica, propondo, como conclusão, a necessária correlação de razão e religião-metafísica como o caminho e conteúdo do universalismo epistemológico-moral.
\end{abstract}

Palavras-chave: Religiões; Racionalismo; Modernidade; Universalismo; Direitos Humanos.

\begin{abstract}
This paper has two main purposes, the first is to develop a criticism on the notion of modernity, or Western rationalism, presented in contemporary theories of modernity, characterized by the idea of autonomy and self-sufficiency of reason regarding the foundation of a binding notion of social normativity. The study criticizes the main perception of these theories of modernity, namely, the proposition that profane and secularized rationalism, marked by an impartial, neutral, formal and impersonal perspective in axiological-methodological terms, is enough to ensure this same epistemological-moral Universalism without religion and metaphysics. The second purpose consists in arguing in favor of a political and religious Universalism that points to the incapacity of this purist and independent notion of reason in generating and sustaining, without foundation and application based on metaphysics and religion, a universal content of Human Rights. The work is grounded on bibliographical analysis of contemporary theories of modernity, from a criticism to their central presumption, which is the autonomy, self-referentiality and self-subsistence of reason relatively to religion and metaphysics, proposing, as a conclusion, the correlation of reason and religion-metaphysics as the path and the content of epistemological-moral Universalism.
\end{abstract}

Keywords: Institutionalized and Universalist Religions; Rationalism; Modernity; Universalism; Human Rights.

Artigo submetido em 02 de julho de 2017 e aprovado em 29 de abril de 2019.

* Doutor em Filosofia (PUCRS). Professor de Filosofia e de Sociologia no Departamento de Filosofia da Universidade Federal de Rondônia (UNIR). País de origem: Brasil. E-mail: leno_danner@yahoo.com.br

** Doutor em Filosofia pela Université de Paris I - Pantheon Sorbonne. Professor no Programa de Pós-Graduação em Filosofia da Pontifícia Universidade Católica do Rio Grande do Sul (PUCRS). País de origem: Brasil. E-mail: abavaresco@pucrs.br

*** Doutor em Filosofia (PUCRS). Professor de Filosofia no Departamento de Filosofia da Universidade Federal de Rondônia (UNIR). País de origem: Brasil. E-mail: fernando.danner@gmail.com 


\section{Introdução}

Defenderemos, no texto, o conceito de universalismo político-religioso como alternativa ao racionalismo ocidental e à sua noção purista e caricata de universalismo epistemológico-moral que não apenas prescinde da cooperação e do suporte das religiões e de outras formas simbólico-culturais de expressão, constituindo-se de modo autônomo e independente em relação a elas, mas também que, de um modo geral, está em oposição a elas. Nas teorias da modernidade ocidentais e nas filosofias políticas nela baseadas - como Max Weber, Jürgen Habermas e John Rawls, por exemplo - a modernidade constitui-se em um processo, um princípio e um valor autorreferenciais e autosubsistentes, independentes da religião e da metafísica, de modo a se colocarem como a única forma de universalismo epistemológico-moral, dado seu caráter pós-metafísico. Essa sua condição a alça a paradigma basilar para a crítica, a justificação e o enquadramento tanto do culturalismo quanto do pluralismo, de modo a periferizar as formas de vida culturais em suas particularidades enquanto geradores, desde si mesmas e por si mesmas, de perspectivas universalistas. Nesse sentido, nas teorias da modernidade europeias, a razão - e uma razão pura, purgada da metafísicateologia e independente aos contextos antropológicos, étnicos e culturais particulares, coloca-se como a única base para a fundamentação e a justificação do universalismo, bem como o guarda-chuva normativo por excelência para o próprio pluralismo.

Acreditamos que essa nossa percepção de se apontar para a necessidade de uma profunda correlação entre razão, religião e metafísica (isso que chamamos de universalismo político-religioso) tem seu sentido exatamente como contraponto de esse pressuposto central assumido por teorias da modernidade contemporâneas, pressuposto esse que influenciou toda uma ampla gama de autores ligados a tais posições (como Axel Honneth e Rainer Forst, apenas para citar dois exemplos), ou mesmo o cerne da discussão sobre uma ética pós-metafísica para o mundo globalizado, que não seria possível de ser sustentada nem pela religião e nem pela metafísica. Esse pressuposto consiste em que o processo de modernidade- 
modernização ocidental significa um trabalho interno dessa mesma modernidade em termos de autopurificação e de desenvolvimento da razão contra a religião e a metafísica, um trabalho feito por uma razão autorreferencial e autossubsistente, endógena e autônoma, capaz, por si mesma e desde si mesma, sem qualquer outro auxílio, de fundar o universalismo epistemológico-moral por meio de uma cultura e de uma consciência cognitivo-moral descentradas, não etnocêntricas e não egocêntricas, marcadas basicamente por um procedimentalismo imparcial, neutro, formal e impessoal em termos metodológico-axiológicos. Em outras palavras, nossa crítica atinge o núcleo das teorias da modernidade europeias contemporâneas, a saber, de que somente a cultura e o homem racionais (leia-se: europeus, como europeus, em termos modelares) podem gerar, pensar, fundamentar e agir em termos universais, mas não a cultura e o homem religiosos e/ou metafísicos (o outro da modernidade); e, em consequência, de que somente o paradigma normativo da modernidade tem condições de sustentar e de legitimar um autêntico universalismo epistemológico-moral pós-metafísico, pois que somente ele, por sua formalidade, neutralidade, imparcialidade e impessoalidade, consegue alcançar uma perspectiva não contextualista, situação que as religiões e as diferentes formas de metafísica não conseguiriam, por serem perspectivas essencialistas e naturalizadas.

Gostaríamos de explicitar o significado de alguns conceitos que nortearão nossa reflexão. O primeiro deles é o conceito de universalismo. Queremos entender, com ele, a ideia de que valores e práticas podem ser justificados e adquirir validade em um contexto intercultural e eventualmente transhistórico. No caso da tradição filosófica ocidental, respaldada e utilizada por Habermas, à qual este se filia, a objetividade é a condição da justificação, e objetividade teria exatamente esse sentido de uma validade intercultural e transhistórica, uma vez que o culturalismo estrito impediria a possibilidade de valores-meta, que serviriam como base para a crítica, o enquadramento e a transformação desse mesmo contexto. Ora, é importante lembrar que um universalismo epistemológico-moral pós-metafísico não significa a recusa dessa intuição fundamental na tradição filosófica, teológica e científica ocidentais, mas sua reformulação em termos do 
procedimentalismo imparcial, neutro, formal e impessoal, de que falamos acima. O segundo conceito fundamental é o de modernidade, que utilizamos significando o processo de racionalização cultural marcado e dinamizado pela correlação de secularização cultural e institucional e de individualismo axiológico, permeados por uma ideia de razão dialógica, histórica e profana (democracia, direitos humanos e Estado de direito se enquadrariam aqui). O terceiro conceito que utilizaremos é o de religiões institucionalizadas e universalistas querendo, com ele, significar as grandes religiões mundiais que se assumem como universais, por meio da correlação de fundamentações essencialistas e naturalizadas, da institucionalização do processo de legitimação, de justificação e de fomento social do credo e de trabalho missionário e messiânico relativamente ao mundo como um todo (Igreja Católica, Luteranismo, Anglicanismo, Islamismo, Judaísmo etc.). Por fim, o quinto conceito central em nosso texto é o de fundamentações essencialistas $e$ naturalizadas. Por esse termo, compreendemos e significamos o fato de que valores, práticas e símbolos são dependentes ou da religião e da metafísica, ou da biologia, ou até de ambas - por isso que valores essencialistas e naturalizados possuem eventualmente um sentido a-histórico e se pretendem de alcance intercultural.

\section{Autossuficiência da razão ou correlação entre razão e religião? Situando o} problema

Algumas das teorias políticas mais influentes da contemporaneidade - nós citaríamos, aqui, as posições de John Rawls e de Jürgen Habermas - conferem um lugar secundário às religiões institucionalizadas e universalistas no que tange à constituição e à legitimação das sociedades democráticas, quiçá mesmo ao próprio enquadramento e à própria crítica da modernização ocidental em particular e, a partir dela, da globalização econômico-cultural de um modo mais geral. Se essas teorias não desmerecem e nem negam certo papel político, cultural e normativo às religiões institucionalizadas e universalistas, por outro lado não lhe dão, conforme estamos argumentando, centralidade política, cultural e normativa, como se a democracia e a modernização em particular e a globalização econômico-cultural de 
um modo mais geral acontecessem e fossem dinamizadas a partir de princípios, de práticas, de instituições e de sujeitos outros que as próprias religiões, inclusive como se as religiões fossem um aspecto periférico tanto da constituição da modernidade quanto da dinamização da globalização econômico-cultural. De todo modo, em ambos os autores, a fundamentação do universalismo epistemológicomoral somente tem condições de possibilidade por causa da razão europeia moderna, que se constitui como contraponto e crítica ferrenha das religiões e das metafísicas as mais variadas. As religiões e as metafísicas não teriam condições, dadas suas bases essencialistas e naturalizadas, de legitimar, sustentar e impor o universalismo à multiplicidade das diferenças ${ }^{1}$.

Assim é que, nas teorias políticas liberais - e nos referimos, novamente, a Rawls - a fundamentação do campo do político e a definição e a orientação da estrutura básica da sociedade são construídas a partir de um processo que Rawls considera eminentemente político, caracterizado pela imparcialidade, pela neutralidade, pela formalidade e pela impessoalidade no que tange às formas de vida particulares e, aqui, às concepções de bem plurais que são próprias ao multiculturalismo das sociedades democráticas modernas (RAWLS, 2003, §6-11, p. 20-53). Nestas, as religiões institucionalizadas e universalistas - e as concepções de bem em geral - são importantes, não há dúvida, mas uma teoria política da democracia mostra que a política e a fundamentação do político podem muito bem ser feitas sem o apelo a e sem a necessidade de princípios retirados dos e fundados nos credos religiosos. Essa, em verdade, seria a condição sine qua non para a justificação do campo do político e, por conseguinte, para a aceitação de uma teoria fundamentalmente política da democracia, a saber, que ela seja independente (mas não necessariamente contraposta) às fundamentações essencialistas e naturalizadas, às religiões institucionalizadas e universalistas (RAWLS, 2000a, 201-241; 200ob, p. 45-90).

\footnotetext{
${ }^{1}$ Veja-se, relativamente a isso, a seguinte passagem de Teoria do agir comunicativo, base da teoria da modernidade europeia como universalismo epistemológico-moral pós-metafísico, por Habermas (2012a, p. 383): "O potencial cognitivo gerado com as imagens de mundo racionalizadas de maneira plena e consequente não se torna efetivo já nas sociedades tradicionais, dentro das quais se cumpre o processo de desencantamento. somente nas sociedades modernas ele vem à luz. E esse processo de implementação significa a modernização da sociedade."
} 
Nesse sentido, se uma teoria política depende, para sua justificação intersubjetiva e para a objetividade dos valores e das práticas que propõe, de princípios, de práticas e de sujeitos epistemológico-políticos religiosos, então ela certamente é mais uma concepção de bem entre outras. A autêntica teoria política democrática, que não é uma concepção de bem, que não se funda em bases essencialistas e naturalizadas e que não depende para sua legitimação de pressupostos religioso-metafísicos, é uma construção autônoma, autorreferencial e auto-subsistente (o campo do político por si mesmo e desde si mesmo), servindo, por causa dessa autonomia, dessa autorreferencialidade e dessa auto-subsistência, por causa dessa politicidade estrita, como guarda-chuva normativo-institucional genérico para todas as concepções de bem particulares. Todas estas concepções de bem abrangentes, metafísico-teológicas e essencialistas e naturalizadas, estariam resguardadas, assumidas, protegidas e fomentadas pelo campo puro do político, pelo campo imparcial, neutro, formal e impessoal do político, mas nenhuma delas seria base fundante para a constituição, a fundamentação e a dinamização dele (RAWLS, 200ob, p. 134-176; HABERMAS, 2002a, p. 3-25; 2002b, p. 7-53; 2003a, p. $87 ; 2003$ b, p. 33$)^{2}$.

Uma situação muito similar pode ser percebida na teoria política de Jürgen Habermas, e isso a partir de dois pontos. O primeiro deles diz respeito à sua teoria da modernidade. Com efeito, nela, o processo de constituição, de desenvolvimento e de dinamização da modernidade-modernização ocidental é marcado exatamente pela racionalização das bases religioso-culturais, no sentido de que a modernidade-

\footnotetext{
${ }^{2}$ Na obra O liberalismo político, Rawls separa diretamente política e religião, atribuindo apenas à primeira a capacidade de garantir a justificação vinculante e os motivos fundadores de uma concepção intersubjetiva de normatividade social válida para todos: "O liberalismo político procura uma concepção política de justiça que, assim como esperamos, possa conquistar o apoio de um consenso sobreposto que abarque as doutrinas religiosas, filosóficas e morais razoáveis de uma sociedade regulada por ela. A conquista desse apoio permitirá responder à nossa questão fundamental: como cidadãos, que continuam profundamente divididos em relação às doutrinas religiosas e morais, mantêm, apesar disso, uma sociedade justa e estável? Para essa finalidade, em geral é necessário renunciar às visões filosóficas e morais abrangentes que estamos habituados a usar para debater questões políticas fundamentais na vida pública." (RAWLS, 2000b, p. 52-53). No mesmo sentido se expressa Habermas (2002b, p. 19-20; destaques do autor), em sua obra A inclusão do outro: estudos de teoria política: "Com a passagem para o pluralismo ideológico nas sociedades modernas, a religião e o ethos nela enraizado se decompõem enquanto fundamento público de uma moral partilhada por todos. Em todo caso, a validação de regras morais obrigatórias para todos não pode mais ser explicada com fundamentos e interpretações que pressupõem a existência e o papel de um deus transcendental, criador e salvador. Sob estas condições, a filosofia moral depende de um 'nível de fundamentação pós-metafísico'. Isto quer dizer, em primeira instância, que lhe são negados, do lado do método, o ponto de vista divino; do lado do conteúdo, o recurso à ordem da criação e à história da salvação; e, do lado da estratégia teórica, a remissão aos conceitos essenciais que perpassam a diferenciação lógica entre os diversos tipos elocucionais de proposições. A filosofia moral deve justificar o sentido cognitivo da validação dos julgamentos e dos posicionamentos morais sem recorrer a apetrechos como esses."
} 
modernização é um processo que acontece contra as religiões, contra as fundamentações essencialistas e naturalizadas, contra a metafísica e a teologia. Na teoria da modernidade de Habermas, portanto, o desencantamento do mundo, por meio da centralidade da racionalidade cultural-comunicativa, leva à instauração da secularização cultural-institucional, isto é, à derrocada da religião em termos de esfera público-política, com a consolidação da política, do Estado democrático de direito e da ciência como as bases constituintes e dinamizadoras das sociedades modernas - assim como à consequente consolidação da razão (e não da religião) como o princípio definidor e dinamizador da consciência cognitivomoral do homem moderno (HABERMAS, 2012a, p. 448; 2012b, p. 280-323). Aqui, modernidade-modernização significa diretamente uma luta contra o dogmatismo, o fundamentalismo e o institucionalismo forte gerados e sustentados pelas religiões institucionalizadas e universalistas, com a consolidação do racionalismo como o contexto, o princípio e a prática fundantes e definidores da constituição, da dinâmica e da evolução dessa mesma sociedade moderna e da própria consciência cognitivo-moral do homem moderno - modernidade, por conseguinte, significa racionalização, cada vez mais racionalização, e menos fundamentalismo e dogmatismo, isto é, menos religião e metafísica (ou, aparentemente, esse seria o caminho linear e autorreferencial, reto e direto da modernização!) (HABERMAS, 2012b, p. 141). 3

E, nesse sentido, a dinâmica central da modernidade-modernização consiste exatamente na politização e na profanização (na secularização) das estruturas, dos valores, das práticas, das instituições e dos sujeitos epistemológico-políticos próprios a uma sociedade-cultura moderna e modernizante. Inclusive, aqui, a própria noção de universalismo epistemológico-moral defendida por Habermas como resultado do processo de modernidade-modernização ocidental, como autêntico produto da modernidade cultural europeia, caracterizada e definida pela

\footnotetext{
${ }^{3}$ Veja-se essa interessantíssima passagem d'O discurso filosófico da modernidade: doze ensaios, de Habermas (2002a, p. 122): “As forças de integração social debilitaram-se em virtude de um processo de esclarecimento que, na medida em que não foi produzido arbitrariamente, tampouco pode ser cancelado. É próprio ao esclarecimento a irreversibilidade de processos de aprendizado que se fundam no fato de que os discernimentos não podem ser esquecidos a bel-prazer, mas só reprimidos ou corrigidos por discernimentos melhores. Por isso, o esclarecimento só pode compensar seus déficits mediante um esclarecimento radicalizado [...]."
} 
correlação de racionalização cultural-comunicativa, individuação reflexiva e fundante e procedimentalismo imparcial, neutro, formal e impessoal, é uma concepção que prescinde do embasamento em e do auxílio de práticas, valores e sujeitos religiosos (HABERMAS, 2012b, p. 87). A modernidade é tanto uma sociedade-cultura quanto, a partir daqui, uma consciência cognitivo-moral descentradas, pós-convencionais e pós-tradicionais que não necessitam diretamente de bases, de valores, de práticas e de argumentos religiosos como condição de sua viabilidade, de sua consecução e de seu funcionamento. Em princípio, a modernidade cultural propicia e fomenta uma postura racional da conduta dos indivíduos e dos grupos que lhes faz prescindir de conteúdos, de práticas e de fundamentos religiosos, essencialistas e naturalizados, em termos da práxis, nas suas relações intersubjetivas e mesmo no que tange às próprias perspectivas e escolhas existenciais tomadas por cada indivíduo (HABERMAS, 2012a, p. 90-141; 2012b, p. 87-196; 2002a, p. 476-483; 2002b, p. 134-135).

Aqui, como acontecia com o liberalismo político de Rawls, se por um lado as religiões são importantes socialmente, por outro não são tão necessárias e nem tão centrais à noção de modernidade ocidental, marcada pelo sentido basilar e pela dinâmica fundante constituídos em termos de modernidade cultural, pela razão não religiosa, purgada da metafísica e da teologia. E daqui, aliás, devém o segundo ponto importante da teoria política de Habermas. Ele pode ser percebido na discussão por ele entabulada com o então cardeal Joseph Ratzinger, futuro Papa Bento XVI, acerca das bases socioculturais da modernidade de um modo geral e do Estado democrático de direito (como um dos herdeiros fundamentais da modernidade europeia) em particular. Para Habermas, o Estado democrático de direito, em suas bases políticas e normativas, calcado exatamente naquela noção política, secular e profana de modernidade cultural, é plenamente capaz de, por si mesmo e a partir de si mesmo, em um movimento autorreferencial e autosubsistente em que a racionalidade é sua única base, princípio e meta, justificar-se e, em consequência, gerar uma cultura público-política madura, cívica que, de sua parte, leva à afirmação do e confere centralidade ao Estado democrático de direito de modo autônomo relativamente à religião e à metafísica, às perspectivas 
essencialistas e naturalizadas. É, note-se bem, um Estado democrático de direito profano, político e politizante, fundamentalmente depurado de quaisquer restos metafísico-teológicos, essencialistas e naturalizados; no mesmo sentido, o civismo e, nesse caso, a vinculação sociopolítica e o endosso das instituições públicopolíticas dos cidadãos e por parte destes são políticos, eles também purgados e independentes em relação às bases, aos princípios e às práticas religiosas. Em síntese, aqui, a modernidade é um processo que se constitui contra as religiões e que se funda e se dinamiza exatamente na autonomia em relação às religiões e na prescindibilidade das bases e das motivações essencialistas e naturalizadas no que tange à legitimação dos processos políticos, culturais, sociais e institucionais. "Uma justiça política que anda pelas próprias pernas", ele diz, "não precisa mais da cobertura de imagens de mundo religiosas ou metafísicas” (HABERMAS, 2002b, p. 116, destaques nossos).

De modo complementar - e não contrário ou excludente - Ratzinger, naquele diálogo com Habermas citado acima, que podemos encontrar na obra Dialética da secularização: sobre razão e religião, explicitou muito bem a existência de uma condição antropológico-ontológica que é mais basilar que o próprio âmbito do político e que, em grande medida, gera, sustenta e dinamiza esse mesmo âmbito do político. Explicitou muito bem, aliás, a própria correlação de modernidade, religião e política, no sentido de que tanto a consolidação da modernidade quanto seu desenvolvimento e sua evolução são caudatários de um processo muito mais complexo do que a racionalização sociocultural progressiva e gradativa, linear e autorreferencial, reta e direta assumida pelas teorias da modernidade como chave-de-leitura e princípio político-normativo fundantes e orientadores do discurso filosófico-sociológico e da autocompreensão normativa da modernidade sobre si mesma. Nesse sentido, tanto a cultura europeia moderna quanto o universalismo epistemológico-moral dali gestados não podem ser explicados exclusiva e talvez nem predominantemente apenas a partir desse processo reto e direto de racionalização sociocultural com o qual a modernidade é definida de modo fundamental (RATZINGER, 2007, p. 63-64, p. 70-75; CATROGA, 2006, p. 15-18, p. 269; MARRAMAO, 1995, p. 29-58). 
Nas teorias da modernidade e na autocompreensão normativa da modernidade europeia, com efeito, o racionalismo seria o antípoda da religião e da metafísica, e a fundamentação política das normas, das práticas e dos valores seria, no mesmo diapasão, o antípoda das bases essencialistas e naturalizadas e da autoridade hierárquica e verticalizada assumidas e fomentadas pela religião e pela metafísica. Com isso, a razão seria não apenas a instância fundamental da legitimação da objetividade epistemológica e da intersubjetividade ético-política, mas também e diretamente o princípio de reflexivização, de correção e de controle de qualquer situação patológica, em particular da religião, do fundamentalismo, do dogmatismo (HABERMAS, 2012a, p. 227). A razão não apenas é o antípoda da fé, da religião, mas também o princípio que permite controlá-las, geri-las e orientá-las, como se a fé e a religião contivessem em si mesmas e, em verdade, como se fossem em si mesmas práticas, valores e dinâmicas que levariam diretamente à violência, à escuridão e a uma postura acrítica sobre si e sobre os outros, ou, pelo menos, à centralidade do contextualismo, de valores e de práticas essencialistas e naturalizados imunes à crítica, insensíveis à alteridade e incapazes de transformação, de mudança. A razão regularia, enquadraria e orientaria tudo, em particular a religião, permitindo uma perspectiva crítica, reflexiva e corretiva em relação à religião e à cultura - eis um ensinamento e uma conclusão fundamentais das teorias da modernidade sobre o racionalismo ocidental, uma prova a mais, segundo elas, do fato de que ele tornou-se autônomo das bases essencialistas e naturalizadas, da religião e da metafísica, na modernidade, colocando-se como plenamente capaz de embasar e orientar a fundamentação de normas, práticas e valores, a realização da crítica social, da emancipação política e da integração cultural (HABERMAS, 2002a, p. 468-470; 2002b, p. 134-135).

Pois bem, e, nesse caso de um racionalismo que enquadra, respalda e orienta a tudo e todos, quem controlaria a própria razão, quando ela se torna patológica? As teorias da modernidade respondem: a razão mesma. Com efeito, retomando novamente Habermas, a modernidade é marcada, para ele, por um processo de racionalização sociocultural não totalizante e não unidimensional, em que se podem distinguir pelo menos dois princípios de integração, a saber, a 
racionalização cultural-comunicativa (própria da modernidade cultural), de cunho eminentemente normativo, e a razão instrumental (própria à modernização econômico-social, ao capitalismo e ao Estado), de sentido e de dinâmica não políticos e não normativos. Essa separação significa, por um lado, que a modernidade cultural é a base ontogenética da modernização econômico-social, que a racionalização cultural-comunicativa gerou a racionalidade instrumental; por outro, ela significa que há uma separação entre as duas formas de racionalidade, situação que, somada à primazia ontogenética da racionalização culturalcomunicativa em relação à racionalidade instrumental, aponta para o fato de que a modernidade cultural é capaz de autorreflexividade, autocrítica e autocorreção, tendo plenas condições de enquadramento e de orientação das patologias psicossociais modernas, causadas exclusivamente pela racionalidade instrumental (HABERMAS, 2012a, p. 588-591; 2012b, p. 330-355; 2002a, p. 482-483). A razão moderna, portanto, nas teorias da modernidade que citamos (particularmente Habermas), é plenamente capaz de controlar-se a si mesma, desde si mesma, realizando uma práxis autorreflexiva, autocorretiva, emancipatória e universalista, para si em primeiro lugar, para o contexto da globalização econômico-cultural em segundo lugar. Ora, é aqui que Ratzinger chama a atenção exatamente para essa contradição da modernidade, isto é, para sua suposta abertura paradigmática ao pluralismo e, ao mesmo tempo, para totalização e unidimensionalização como a única base societal-cultural e paradigmática em termos de crítica, enquadramento, reflexividade e orientação, a partir de um discurso dual que purifica a modernidade de toda e qualquer contradição interna, como se ela não tivesse e não gerasse nenhum pecado e nenhuma mancha - situação que essa estilização em termos de dualidade gera, legitima e assume diretamente. Mas não existe uma razão purista e muito menos dual (RATZINGER, 2007, p. 78-81).

Nesse sentido, é exatamente em um momento de crise da razão que, para Ratzinger, a religião reassume o seu legítimo papel em termos de integração sociocultural e de fundamentação axiológica. Desse modo, ela permitiria a construção de um discurso e de uma práxis mais realista tanto sobre o processo de modernização ocidental quanto sobre a globalização econômico-cultural e, aqui, 
sobre o projeto de uma base normativa mínima para essa condição atual da humanidade. E esse discurso e essa práxis religiosos também serviriam para o próprio enquadramento, crítica e correção da modernidade, agora não mais exclusivamente por si mesma, mas a partir exatamente da contribuição $e$ participação religiosas. Por isso, se o discurso filosófico-sociológico da modernidade tem razão em afirmar que o fundamentalismo e o dogmatismo podem, em muitas situações, descambar para situações de violência e de exclusão e de que, por conseguinte, aqui, a racionalização permite o controle e a moderação deles (HABERMAS, 2012a, p. 227-249; 2002a, p. 507-508; 2002b, p. 331), por outro, o discurso filosófico-sociológico da modernidade não tem razão em sustentar que a razão é instância suficiente para a integração sociocultural e para a fundamentação dos valores, bem como de que ela seja o único princípio garantidor da crítica, do enquadramento e da orientação da religião e de si mesma (RATZINGER, 2007, p. 73-75; JOÃO PAULO II, 1998, §§5-6). A razão tem patologias e pontos cegos que somente podem ser esclarecidos e corrigidos desde fora, desde a religião, desde outras posições normativo-paradigmáticas, e viceversa. Há, portanto, um processo complementar em que razão e religião se interrelacionam, se orientam e se corrigem mutuamente, contribuindo para o aperfeiçoamento mútuo, para o sustento mútuo (RATZINGER, 2007, p. 87-89; JOÃO PAULO II, §9, §§25-27, §33).

No mesmo sentido, a correção e a complementação mútua de razão e religião permite a desconstrução de outra pressuposição muito própria ao racionalismo ocidental, assumida e afirmada em cheio pelas teorias da modernidade, a saber, de que somente o paradigma normativo da modernidade na correlação de racionalização cultural-comunicativa, individuação forte e reflexiva e procedimentalismo imparcial, neutro, formal e impessoal - consegue fundar, dinamizar e fomentar uma postura de crítica, de reflexividade, de emancipação e, por consequência, de fundamentação epistemológico-moral universalista dos valores, das práticas e dos princípios. As religiões e as fundamentações essencialistas e naturalizadas em geral não o conseguiriam porque elas (a) são dependentes de uma homogeneização e de uma unidimensionalização 
estritas dos valores, das práticas e dos sujeitos epistemológico-políticos, que não levam em conta o e que não são abertas ao pluralismo; além disso, (b) elas, por causa de suas bases essencialistas e naturalizadas, não aceitam racionalização interna dos valores, ou dificilmente a assumem, posto que a racionalização implicaria exatamente na relativização dessas bases e, em muitos casos, em sua deslegitimação direta; finalmente, (c) bases essencialistas e naturalizadas não permitem a construção de um conceito profano, político e normativo de humanidade que seja independente dessas mesmas bases e cujo núcleo duro seja apenas formal, o que significa (d) que as bases essencialistas e naturalizadas não geram uma estrutura societal-cultural e uma consciência cognitivo-moral descentradas e pós-convencionais, não egocêntricas e não etnocêntricas. Em síntese, a cultura e a consciência cognitivo-moral calcadas em bases essencialistas e naturalizadas não permitem que os indivíduos pensem e se coloquem no lugar dos outros como outros; se eles fazem isso, é sempre a partir de sua perspectiva identitária, portanto, de modo egocêntrico e etnocêntrico (HABERMAS, 1989, p. 143-223; 1989, p. 61-132; 2002a, p. 517; 2002b, p. 53).

\section{Universalismo entre religião e modernidade: por um universalismo político- religioso}

É interessante perceber, no que tange à fundamentação da objetividadeintersubjetividade epistemológico-moral, que as teorias da modernidade calcadas no, dependentes e fomentadoras do racionalismo ocidental associam diretamente as posições religioso-culturais várias com fundamentações essencialistas e naturalizadas e essas com contextualismo, com uma noção de comunidade de cultura, de sangue e de destinação que, se por um lado aspira à universalidade, por outro é bastante cega e mesmo insensível relativamente ao pluralismo, incapaz de assumi-lo, de utilizá-lo e de realizá-lo efetivamente - a universalidade das posições contextualistas significaria sempre, por conseguinte, nessa interpretação que delas fazem as teorias da modernidade fundadas no racionalismo ocidental, a imposição de um paradigma antropológico-ontológico, sociocultural e epistemológico-político unidimensional e totalizante ao pluralismo, periferizando e ao cabo negando esse 
mesmo pluralismo. Nesse sentido, como contextualismo estrito, as posições religioso-culturais, de cunho, de sentido e de dinâmica essencialistas e naturalizados, apresentam três déficits fundamentais que lhes impedem de alcançar e assumir, desde suas bases essencialistas e naturalizadas e por si mesmas, a universalidade epistemológico-moral, isto é, uma estrutura institucional-cultural e uma consciência cognitivo-moral descentradas e pós-convencionais, não egocêntricas e não etnocêntricas, a saber: (a) não conseguem - e talvez nem querem - abdicar dessas fundamentações essencialistas e naturalizadas tanto como base de sua autocompreensão normativa quanto como mote para sua vinculação social, cultural e política e, aqui, para seu enquadramento e para sua compreensão das diferenças, do pluralismo; (b) assumem a própria comunidade de cultura, de sangue e de destinação como um modelo universal a ser prosseguido de modo missionário e messiânico e como a base salvífica de tudo e de todos; e (c) são avessas à racionalização no duplo sentido do termo, como descentralização e abdicação institucionais do monopólio da interpretação, da fundamentação e do fomento social do credo e como moderação discursiva e prático-moral por causa exatamente da centralidade das diferenças.

Nesse sentido, para as teorias da modernidade, o processo de modernização ocidental como desenvolvimento linear e autorreferencial, reto e direto de uma razão purificada da religião e da metafísica, de uma razão não religiosa e não metafísica, de uma razão política-politizante, secularizada e profana que pode andar por suas próprias pernas, ao mesmo tempo em que torna a razão independente, desligada e autônoma em relação à religião e à metafísica, em relação às bases essencialistas e naturalizadas das posições religioso-culturais sempre contextualistas, a alça a um grau de generalidade mais amplo que aquelas. Nesse sentido, se as posições religioso-culturais sempre contextualistas, dada sua base essencialista e naturalizada, seu fundamentalismo institucional e seu dogmatismo no que diz respeito à compreensão dos valores, das práticas e dos sujeitos epistemológico-políticos, não conseguem estimular uma perspectiva intersubjetiva que seja independente dessas suas condições, características e dinâmicas, a modernidade cultural, ao contrário, uma vez calcada na e dependente 
da racionalização cultural-comunicativa e da subjetividade reflexiva e fundante, faz com que os processos socioculturais, as relações intersubjetivas e a postura de seus indivíduos adquiram uma dupla e interligada característica. Por um lado, que elas sejam fundadas apenas e tão somente na capacidade de estes indivíduos interagirem e dialogarem uns com os outros em busca da fundamentação do universal; e, por outro, ao fazerem isso, assumam as diferenças e o multiculturalismo como o ponto de partida, a base dinamizadora e o próprio ponto de chegada dos processos de socialização e de subjetivação, dos processos de fundamentação axiológica em geral. É por isso que Rawls, Habermas, Forst e Honneth acreditam que, em última instância, esse modelo de razão purista e universalista é a condição fundante, a base dinamizadora e o paradigma críticoreflexivo para o universalismo, que não podem ser gerados e sustentados pelas posições religioso-culturais sempre contextualistas (FORST, 2010, p. 210-211; HONNETH, 2003, p. 275).

Porém, como estamos fazendo ver ao longo do texto, a ideia de uma modernidade pura e diretamente racional não se sustenta, assim como não pode ser defendida em sentido estrito a ideia de que somente uma postura fundamentalmente racional permite a fundação da objetividade epistemológicomoral, a crítica, a reflexividade e a emancipação. Em primeiro lugar, o próprio racionalismo ocidental tem o mesmo sentido das posições essencialistas e naturalizadas, isto é, ele define o caminho e o sentido da fundamentação, a saber, a racionalização dos valores e das práticas e um procedimento que, conforme dissemos acima, é imparcial, neutro, formal e impessoal relativamente aos valores e às vinculações concretas dos sujeitos epistemológico-políticos. Ora, isto também é definir o caminho, o sentido e o conteúdo axiológico resultantes da discussão, posto que um procedimento que exige a superação das bases essencialistas e naturalizadas e das vinculações concretas como condição da objetividade e da justificação já dá de antemão o rumo e o conteúdo da própria fundamentação, do próprio universalismo. E, de todo modo, nenhum dos dois caminhos supostamente diferentes, o das posições essencialistas e naturalizadas e o do racionalismo ocidental, está equivocado ou é totalmente suficiente, por si mesmo e desde si 
mesmo, para a realização da fundamentação do universalismo epistemológicomoral. Dos dois modos é possível chegar-se a ele, e de forma bem-sucedida e profícua. No mesmo sentido, nós, como indivíduos e grupos socioculturais, sempre emergimos de um contexto antropológico-ontológico e sociocultural específico e por ele somos delimitados de modo fundamental, sejamos filhos da modernidade purista em termos racionais, sejamos filhos de posições religioso-culturais contextualistas - e essa condição nunca foi empecilho para ninguém relacionar-se com as diferenças e pensar de modo universal. Portanto, esse discurso e essa compreensão seletivos das teorias da modernidade, relativamente a um sentido e a uma dinâmica puristas da razão desde si mesma, por si mesma e frente ao pluralismo, assim como seu pressuposto fundante que associa bases essencialistas e naturalizadas com contextualismo, concretismo, dogmatismo e fundamentalismo estritos, negando-lhes a possibilidade de alcançarem o ponto de vista epistemológico-moral universalista, são merecedores de crítica e de complemento. Ora, aqui pode ser inserida, nesse sentido, a proposta de Bento XVI, de uma cooperação e de uma correção mútua de razão e religião, no sentido de que, se por um lado a razão corrige e complementa proficuamente as religiões quanto estas instauram um fundamentalismo cego e violento, por outro essas mesmas religiões esclarecem o Esclarecimento. E aqui pode ser inserida, mais ainda, sua observação de que tanto o racionalismo ocidental quanto o Cristianismo não são universais, embora se autocompreendam enquanto tal. Vejamos a fundamental afirmação de Bento XVI: “[...] parece-me inegável que a universalidade das duas grandes culturas do Ocidente, ou seja, da fé cristã e da racionalidade secular, de fato não existe, por mais que ambas exerçam sua influência, cada uma à sua maneira, no mundo todo e em todas as culturas.” (RATZINGER, 2007, p. 84-85).

É importante frisar, em primeiro lugar, que Ratzinger não está negando a universalidade - em termos de pretensão e de alcance - nem do racionalismo e nem do Cristianismo, mas afirmando exatamente que uma tal universalidade não é auto-evidente e nem clara a priori. Por isso, em segundo lugar, o que ele quer significar e defender com tal observação é que (a) somente o trabalho correlato entre razão e religiões pode fundar a objetividade dos valores e das práticas, isto é, 
pode fundar o universalismo epistemológico-moral desde uma perspectiva política, cultural e religiosa que é, ao mesmo tempo, essencialista e naturalizada e política e profana, bem como, em consequência, (b) que, sempre que falamos em universalismo epistemológico-moral e em sua fundamentação e validade, temos de incluir todas as sociedades, todas as culturas e todos os povos no processo de construção e de justificação das normas e das práticas. Incluí-los sem solicitar-lhes, como o faz o racionalismo, a neutralidade, a imparcialidade, a formalidade e a impessoalidade políticas e nem a racionalização axiológica, que significam e implicam em negar-se que eles, desde si mesmos e por si mesmos, e sem necessidade de apelar ao próprio racionalismo ocidental, possam fundar e justificar a escolha de princípios e de práticas considerados universais. Incluí-los, ainda, sem impor desde fora e a partir de outras bases antropológico-ontológicas, socioculturais e epistemológico-políticas valores universais para toda a humanidade, mas que, paradoxalmente, foram fundados e descobertos em e por uma cultura particular, a europeia, e impostos para todas as demais sociedades, culturas e povos sem mediações e sem qualquer diálogo-práxis minimamente equitativo, inclusivo e acolhedor das diferenças.

O universalismo moderno, racional, e o universalismo cristão, essencialista e naturalizado, não são, portanto, autoevidentes e totalmente claros para todos os povos, para todas as sociedades e para todas as culturas - é isso que Ratzinger quis dizer na passagem acima. De um modo mais geral, se pode inferir daqui que o universalismo - seja ele fundado em que base for e parta ele de qualquer sociedade, cultura, religião e paradigma antropológico-ontológico e epistemológico-moral não é auto-evidente, não é absolutamente claro e não é um dado a priori que possa, portanto, ser imposto de maneira verticalizada e extemporânea à própria participação e inclusão de todos os que são envolvidos por essa universalidade. Assim, se esta pode ser fundada, dinamizada e assumida por todos os povos, por todas as culturas e por todas as sociedades, ela terá de ser resultado de uma construção participativa, inclusiva e cooperativa, mas uma construção que não pode ser ditada nem pelo racionalismo ocidental (em sua correlação de racionalização axiológica, de individuação forte e de procedimentalismo imparcial, 
neutro, formal e impessoal) e nem exclusivamente por uma posição essencialista e naturalizada em particular. Terá de ser uma construção em que todos, desde suas perspectivas antropológico-ontológicas, socioculturais e epistemológico-políticas, participam em igualdade de condições e fundam a objetividade exatamente a partir do que são e vivem e de como são e vivem. Um exercício complicado e tenso, sem dúvidas, mas não existirá universalidade sem participação, inclusão e respeito pelas diferenças como diferenças, que se posicionam e fundamentam como tais.

A condição, as experiências e os valores de cada sociedade, cultura e religião colocam-se como o ponto de partida e a base dinamizadora da construção de uma ética comum e de um conjunto mínimo de valores humanos, e somente essa resposta plural e calcada em bases plurais pode, por um lado, enquadrar e reorientar uma globalização econômico-cultural caótica como resultado da modernização ocidental e, por outro, dar conteúdo, justificação, aceitação e obrigatoriedade ao universalismo e ao conjunto de direitos humanos de quem está fora da modernidade ou que lhe é periferia. É por isso que estamos falando em um universalismo político-religioso. Por esse termo, queremos significar, em primeiro lugar, o fato de que existem muitos paradigmas e, portanto, muitas formas, práticas e processos de fundamentação para se chegar à universalidade, capazes de gerar e de sustentar a universalidade. Esta mesma universalidade não é uma prerrogativa do racionalismo ocidental e nem de uma ou outra concepção antropológicoontológica específica, senão que de todas. Um cristão ou um muçulmano ou um xamã indígena podem ter, fundar e dinamizar uma perspectiva crítica, reflexiva, emancipatória e universalista desde suas bases e a partir de suas práticas, princípios, valores e experiências4. Não é necessário, aqui, assumir-se paradigmas normativos e processos societais-culturais extemporâneos à própria forma de vida, aos próprios fundamentos antropológico-ontológicos para se fundar valores e

\footnotetext{
${ }^{4}$ Apenas a título de exemplo, veja-se esse posicionamento do indígena e xamã yanomami Davi Kopenawa (2015, p. 75) como prova de nosso argumento de que a crítica, a reflexividade, a emancipação e o universalismo são possíveis a partir de todas as formas de vida e paradigmas normativos: "Hoje, os brancos acham que deveríamos imitá-los em tudo. Mas não é o que queremos. Eu aprendi a conhecer seus costumes desde a minha infância e falo um pouco a sua língua. Mas não quero de modo algum ser um deles. A meu ver, só poderemos nos tornar brancos no dia em que eles mesmos se transformarem em yanomami. Sei também que, se formos viver em suas cidades, seremos infelizes. Então, eles acabarão com a floresta e nunca mais deixarão nenhum lugar onde possamos viver longe deles. Não poderemos mais caçar, nem plantar nada. Nossos filhos vão passar fome. Quando penso em tudo isso, fico tomado de tristeza e de raiva."
} 
práticas, para dar sentido à própria voz-práxis. Isso seria um golpe de morte às diferenças e ao pluralismo, e a renovação de uma perspectiva unidimensional, totalizante e colonialista - uma tendência, aliás, muito forte à modernidade ocidental, mesmo hoje, epistemológica, política, cultural e economicamente. Para o universalismo político-religioso, cada sociedade, cultura e religião têm uma base de valores, de práticas e de experiências fundantes e dinamizadoras que lhes são totalmente suficientes para sua constituição, para seu desenvolvimento e para sua evolução ao longo do tempo; e que são importantes e inultrapassáveis, inclusive e por isso mesmo, para o diálogo-práxis intercultural, para a fundamentação do universalismo e para a elaboração de um conjunto mínimo e vinculante de direitos humanos, de uma ética para a globalização. Por isso mesmo, todas elas devem participar de uma tal construção, todas elas deve ser ouvidas e valorizadas em igual importância. A autocompreensão de que o universalismo é uma condição, uma especificidade e uma prerrogativa do racionalismo ocidental, como defenderam Max Weber e Jürgen Habermas, simplesmente não se sustenta de modo exclusivo, como já dissemos, e pode contribuir para inferiorizar ou até excluir o outro da modernidade (WEBER, 1984, p. 11-24; HABERMAS, 2012a, p. 94-95).

Em segundo lugar, um universalismo político-religioso significa que não se pode fundar direitos e práticas vinculantes para a globalização e um paradigma normativo que possa garantir crítica, reflexividade e orientação das sociedadesculturas-religiões particulares exclusivamente por meio do racionalismo e a partir de uma perspectiva profana, política e secularizada. Se por um lado esta perspectiva da modernidade não pode ser negada, por outro ela tem de ser entendida como uma perspectiva entre outras, não como a perspectiva por excelência, como o guarda-chuva normativo de todas as visões de mundo particularistas - a visão de mundo moderna como universalista e as visões de mundo não modernas, religioso-metafísicas e essencialistas e naturalizadas como particularistas, contextualistas, a modernidade como abertura e reflexividade, as religiões como fechadas e irreflexivas. Nesse sentido, a política talvez seja apenas o método para a discussão intercultural, mas, na prática, essa mesma discussão intercultural simplesmente não poderia fugir exatamente de uma fundamentação 
essencialista e naturalizada, religiosa e metafísica seja do universalismo epistemológico-moral, seja de seu resultante conjunto de direitos humanos, de práticas e de valores vinculantes interculturalmente. Como Ratzinger chamou a atenção com muita propriedade, a modernidade como racionalismo não é universal, ainda que tente convencer-se e convencer a todos de que ela é autêntico universalismo. Isso não significa desprestigiar a modernidade, que fique bem claro, mas apontar para um senso de realidade básico que desvele a cegueira e o purismo da autocompreensão normativa da modernidade por si mesma e, daqui, seu autoassumido protagonismo e direcionamento universais: o mundo é religioso, profundamente religioso, dependente de modo fundamental seja do suporte das grandes religiões, seja das bases essencialistas e naturalizadas desde elas emanadas para sua motivação diária, como substrato para sua vida cotidiana e como base de seus valores e de suas práticas. Negar isso seria negar o óbvio ululante; ignorar isso seria inviabilizar o próprio universalismo em termos de fundamento, conteúdo e motivação.

Por isso, um universalismo político-religioso afirma que a fundamentação do universalismo epistemológico-moral e do conjunto de direitos humanos não pode prescindir de uma justificação religiosa, essencialista e naturalizada, uma justificação que é construída e dinamizada a partir do diálogo-práxis intercultural em que todos os povos, culturas e religiões são chamados à discussão efetiva, inclusiva e atenciosa para com as diferenças, até porque discussão com as diferenças e desde elas não é racionalização ou unidimensionalização, mas exatamente participação efetiva dessas mesmas diferenças, autoexpressão e autoafirmação desde si mesmas e por si mesmas, desde suas bases antropológicoontológicas, socioculturais e epistemológico-políticas. Aqui, como dissemos acima, o qualificativo político (do termo universalismo político-religioso) é e significa, antes de mais nada, a arena para a discussão e a participação inclusivas, mas não o conteúdo e o resultado final do universalismo e dos direitos humanos. No diálogo com Ratzinger, Habermas disse que a modernidade pode fundar cognitivamente, sustentar normativamente e motivar político-culturalmente seja o Estado democrático de direito, seja o universalismo epistemológico-moral. Ora, quando 
constatamos que o mundo é religioso, e não profano, quando constatamos que ele é plural, e não moderno, quando constatamos o caráter unidimensional (apenas a razão funda o universalismo epistemológico-moral desde um prisma pósmetafísico) e, assim, a limitação do paradigma normativo da modernidade sobre si mesmo e sobre os outros da modernidade, também nos damos conta de que a base, o conteúdo e a motivação do universalismo e dos direitos humanos devem ser, de modo primordial, religioso-metafísicas, essencialistas e naturalizadas.

E daqui adviria a terceira característica fundamental do universalismo político-religioso, a saber, a centralidade das religiões institucionalizadas e universalistas - das grandes religiões mundiais - no que diz respeito à construção, à dinamização e ao fomento seja do diálogo-práxis intercultural e interreligioso, seja de uma política de direitos humanos e de justiça social para a globalização, algo que, conforme já estamos falando, a modernidade como perspectiva euronorcêntrica purista, unidimensional e totalizante, e constituída contra as religiões e contra as culturas não modernas, já não consegue sustentar, motivar e realizar. Por religiões institucionalizadas e universalistas entendemos, repetimos mais uma vez, as grandes religiões mundiais da atualidade, que se constituem sob a forma de instituições que assumem, centralizam e em grande medida monopolizam a legitimação de seus respectivos credos, assumindo uma postura, um sentido e um direcionamento universalistas, missionários e messiânicos (certamente estamos falando da Igreja Católica como uma religião institucionalizada e universalista, entre outras). As religiões institucionalizadas e universalistas não apenas possuem autoridades centrais e uma vinculação global (uma vez que, neste último caso, o grosso da população mundial segue-as), senão que autocompreendem-se e dinamizam-se exatamente por meio do apelo ao universalismo, mas de um universalismo calcado em bases essencialistas e naturalizadas, um universalismocosmopolitismo religioso.

Conforme pensamos, um universalismo político-religioso não pode passar ao largo desse fato puro e simples do mundo contemporâneo, a saber, de que o grosso da população mundial segue tais religiões, vivendo, significando e morrendo 
sob seus signos, valores, práticas e autoridades. No mesmo sentido, para o universalismo político-religioso, as religiões institucionalizadas e universalistas assumem protagonismo central no que tange seja à crítica e ao enquadramento da globalização econômico-cultural caótica e violenta, seja à construção de uma política de paz, de justiça e de direitos humanos em nível global - pensemos, aqui, nesse documento incrível que é a encíclica Laudatio Si, do Papa Francisco, como crítica à modernização-globalização desde um prisma cristão, essencialista e naturalizado, que prova exatamente que a religião pode pensar, agir e fundamentar universalmente (PAPA FRANCISCO, 2016, §§o3-06). As bases, os valores e as práticas destas religiões são fundamentais para a estabilidade de nossas sociedades e para a globalização de um modo geral e, por isso, assumem a função de ponta-delança no repensar delas e na construção e na fundamentação do universalismo para a globalização. Por isso, para o universalismo político-religioso que estamos defendendo, é importante que as religiões institucionalizadas e universalistas comprometam-se e assumam diretamente essa tarefa de crítica, de enquadramento e de orientação da globalização econômico-cultural e de correção da modernidade em crise, bem como, em consequência, que promovam desde as próprias religiões a construção de uma cultura de paz, de justiça social e de direitos humanos que encontra nos próprios conteúdos e nas práticas religiosas fundamentação, substrato e motivação para sua realização e para sua efetivação no dia a dia de nossas sociedades e culturas e da política internacional. Exemplos desse comprometimento e dessa vinculação de religiões institucionalizadas e universalistas podem ser percebidos hoje na Igreja Católica, em particular no diálogo-práxis intercultural e interreligioso do Papa Francisco e, destacamos aqui, em duas encíclicas fundamentais por ele lançadas, a Laudatio Si5 e a Amoris

\footnotetext{
${ }^{5}$ A passagem seguinte, da Laudatio Si, do Papa Francisco, em verdade, vem ao encontro de nossa defesa de que somente um universalismo político-religioso, uma correlação de razão e religiões, de práticas, princípios, valores e fundamentações a um só tempo essencialistas e naturalizados e profano-secularizados pode dar conta da fundamentação do universalismo epistemológico-moral e de um conteúdo mínimo de direitos humanos, inclusive permitindo a legitimação e a defesa de uma ecologia integral - ecologia integral porque não apenas calcada nas e percebidas desde as ciências naturais e exatas, mas porque dependente e dinamizada pelas religiões, pelas fundamentações essencialistas e naturalizadas. O Papa Francisco diz, em Laudatio Si: "[...] uma ecologia integral requer categorias que transcendem a linguagem das ciências exatas ou da biologia e que nos põem em contato com a essência do ser humano" (PAPA FRANCISCO, 2016, §11, destaques nossos).
} 
Laetitia $^{6}$, que, em nosso entender, são dois dos documentos normativos mais importantes e explosivos da e na cultura contemporânea como crítica à modernização-globalização sem limites e como valorização das diferenças dentro da própria Igreja em primeiro lugar e fora dela em segundo lugar.

\section{Considerações finais: sobre a herança e o fundamento do universalismo epistemológico-moral}

Desse modo, um universalismo plural e heterogêneo, um universalismo político-religioso nos parece o ponto de partida mais adequado quando pensamos em uma política de direitos humanos, em valores, práticas e princípios comuns à globalização econômico-cultural hodierna e como forma de se criticá-la, enquadrála e reorientá-la em seus problemas. Esse universalismo plural e heterogêneo, político e religioso, essencialista e naturalizado, secularizado e profano, situa a problemática do sentido comum exatamente no chão duro do multiculturalismo, levando a sério a multiplicidade de visões de mundo que não apenas aspiram à universalidade, senão que exatamente a permitem. Por isso, o universalismo político-religioso reconhece que, sem essas perspectivas plurais, não existirá base comum à globalização, mas sim a imposição unidimensional e totalizante da modernidade em relação ao tradicionalismo em geral, o que significa a primazia da razão moderna (isto é, moderna porque puramente racional, o que, conforme afirmamos ao longo do texto, é um verdadeiro problema, uma limitação) sobre as religiões e as formas de vida culturais não modernas (bases essencialistas e naturalizadas). E esse universalismo conclama as religiões institucionalizadas e universalistas a assumirem essa sua vocação universalista e cosmopolita, como contraponto e correlação à modernização hoje em voga e totalmente hegemônica

\footnotetext{
${ }^{6}$ Veja-se a passagem seguinte, do Papa Francisco $(2017, \S 308$, p. 247), em Amoris Laetitia, em que ele tematiza seja a vocação e o trabalho missionário-universalistas da Igreja, seja a dialética entre fundamentação e aplicação institucionais do credo no dia a dia da vida cotidiana, sempre dinamizados pela moderação, pela misericórdia e pelo discernimento como balizas orientadoras: "Todavia, da nossa consciência do peso das circunstâncias atenuantes - psicológicas, históricas e mesmo biológicas - conclui-se que, sem diminuir o valor do ideal evangélico, é preciso acompanhar, com misericórdia e paciência, as possíveis etapas do crescimento das pessoas, que se vão construindo dia após dia. Compreendo aqueles que preferem uma pastoral mais rígida, que não dê lugar a confusão alguma; mas creio sinceramente que Jesus Cristo quer uma Igreja atenta ao bem que o Espírito derrama no meio da fragilidade: uma Mãe que, ao mesmo tempo que expressa claramente a sua doutrina objetiva, não renuncia ao bem possível, ainda que corra o risco de sujar-se com a lama da estrada."
} 
no nível global. Elas, dada sua estruturação fundamentalmente normativa, constituem-se em base, baluarte e paradigma fundamentais para garantir uma perspectiva crítica, reflexiva, corretiva e emancipatória, seja relativamente à modernidade, seja no que diz respeito aos próprios contextos de que emergem e que representam.

Nesse sentido, se a intenção, diante da globalização econômico-cultural hodierna, consiste em fundar-se seja um universalismo epistemológico-moral vinculante, seja uma concepção de direitos humanos que sirva como solo comum de reivindicações e de interações mútuas, então não se pode passar ao largo das contribuições religiosas e culturais próprias a cada contexto vital, situação que, como dissemos, as religiões institucionalizadas e universalistas necessitam urgentemente promover e dinamizar, dada sua constituição, seu sentido e seu movimento universalistas, cosmopolitas, missionários e messiânicos. Paradoxalmente, a época da razão, a que a modernidade nos conduziu, exige também uma volta às religiões e à metafísica como forma de resolução dos problemas da modernização, como forma de esclarecimento de um Esclarecimento que se concebe como autêntico e puro universalismo e, assim, para a fundamentação de um universalismo plural e de um conjunto de direitos humanos que sejam, de fato, ancorados nas diferenças concretas, em sua condição e levando em consideração suas especificidades, valores e práticas. A modernidade por si mesma e exclusivamente desde si mesma, desde seu purismo, não poderá fazer isso, o que demanda a urgência de as religiões institucionalizadas e universalistas assumirem e conduzirem esse debate em torno a um universalismo políticoreligioso que, esse sim, pode fundar um conjunto de direitos humanos desde bases essencialistas e naturalizadas, sensível, atento e vinculante aos contextos antropológicos particulares. 


\section{REFERÊNCIAS}

CATROGA, Fernando. Entre deuses e césares: secularização, laicidade e religião civil. Coimbra: Edições Almedina, 2006.

FORST, Rainer. Contextos da justiça: filosofia política para além de liberalismo e comunitarismo. São Paulo: Boitempo, 2010.

HABERMAS, Jürgen. A inclusão do outro: estudos de teoria política. São Paulo: Loyola, $2002 b$.

HABERMAS, Jürgen. Consciência moral e agir comunicativo. Rio de Janeiro: Tempo Brasileiro, 1989.

HABERMAS, Jürgen. Direito e democracia: entre facticidade e validade. Rio de Janeiro: Tempo Brasileiro, v. 1, 2003a.

HABERMAS, Jürgen. Direito e democracia: entre facticidade e validade. Rio de Janeiro: Tempo Brasileiro, v.2, $2003 \mathrm{~b}$.

HABERMAS, Jürgen. O discurso filosófico da modernidade: doze lições. São Paulo: Companhia das Letras, 2002a.

HABERMAS, Jürgen. Pensamento pós-metafísico: estudos filosóficos. Rio de Janeiro: Tempo Brasileiro, 1990.

HABERMAS, Jürgen. Teoria do agir comunicativo: racionalidade da ação e racionalização social. São Paulo: Martins Fontes, v. 1, 2012a.

HABERMAS, Jürgen. Teoria do agir comunicativo: sobre a crítica da razão funcionalista. São Paulo: Martins Fontes, v. 2, 2012b.

HABERMAS, Jürgen; RATZINGER, Joseph. Dialética da secularização: sobre razão e religião. São Paulo: Idéias \& Letras, 2007.

HONNETH, Axel. Luta por reconhecimento: a gramática moral dos conflitos sociais. São Paulo: Editora 34, 2003.

JOÃO PAULO II. Carta Encíclica Fides et Ratio. Vaticano: Tipografia Vaticana, 1998. Disponível em<http://w2.vatican.va/content/johnpaulii/pt/encyclicals/documents/hf_jpii_enc_14091998_fides-et-ratio.html.> Acesso em: 30/o6/2017

KOPENAWA, Davi; ALBERT, Bruce. A queda do céu: palavras de um xamã Yanomami. São Paulo: Companhia das Letras, 2015.

MARRAMAO, Giacomo. Poder e secularização: as categorias do tempo. São Paulo: Editora da UNESP, 1995. 
PAPA FRANCISCO. Amoris Laetitia. Vaticano: Tipografia Vaticana, 2017. Disponível em: <http://www.agencia.ecclesia.pt/netimages/file/papa-francesco_esortazioneap_20160319_amoris-laetitia_po.pdf $>$. Acesso em: 28/03/2017.

PAPA FRANCISCO. Carta Encíclica Laudatio Si: sobre o cuidado da casa comum. Vaticano: Tipografia Vaticana, 2016. Disponível em: <http://w2.vatican.va/content/ francesco/pt/encyclicals/documents/papa-francesco_20150524_enciclica-laudatosi.html> Acesso em: 30/06/2017.

RAWLS, John. Justiça como equidade: uma reformulação. São Paulo: Martins Fontes, 2003.

RAWLS, John. Justiça e democracia. São Paulo: Martins Fontes, 2000a.

RAWLS, John. O Liberalismo político. São Paulo: Martins Fontes, 200ob.

WEBER, Max. Ensayos sobre sociología de la religión (T. I). Madrid: Taurus, 1984. 